\title{
The Evaluation of Water Sorption/ Solubility on Various Acrylic Resins
}

\author{
Suleyman Hakan Tuna ${ }^{a}$ \\ Filiz Keyf ${ }^{b}$ \\ Hasan Onder Gumusc \\ Cengiz Uzun ${ }^{d}$
}

\begin{abstract}
Objectives: The absorption of water by acrylic resins is a phenomenon of considerable importance since it is accompanied by dimensional changes, a further undesirable effect of absorbed water in acrylic resins to reduce the tensile strength of the material. Solubility is also an important property because it represents the mass of soluble materials from the polymers.

Methods: Ten acrylic resin-based materials were evaluated: two heat cure acrylic resins (De Trey QC-20, Meliodent Heat Cure) and eight self cure acrylic resins (Meliodent Cold, Akrileks, Akribel, Akribel Transparent, Vertex Trayplast, Formatray, Dentalon Plus, Palavit G). To evaluate water sorption and water solubility, thirty square-shaped specimens $(20 \times 20 \times 1.5 \mathrm{~mm})$ were fabricated from the wax specimens. One way ANOVA test, Tukey test and Pearson correlation coefficient performed for data.

Results: Water sorption mean values varied from $11.33 \pm 0.33$ to $30.46 \pm 0.55 \mu \mathrm{g} / \mathrm{mm}^{3}$. Water solubility mean values varied from $-0.05 \pm 0.23$ to $3.69 \pm 0.12 \mu \mathrm{g} / \mathrm{mm}^{3}$. There was statistically significant difference between mean values of the materials $(P<.05)$. There was no linear correlation between sorption and solubility values.

Conclusions: The results of the water sorption and water solubility values of both self-cured and heat-cured acrylic resins were in accordance with the ISO specification. No correlation found between water sorption and water solubility values. (Eur J Dent 2008;2:191-197)
\end{abstract}

Key Words: Acrylic resin; Water sorption; Water solubility; Heat-cure acrylic; Self-cure acrylic.

a PhD, Assistant Professor, Depertmant of Prosthodontics, Faculty of Dentistry, Suleyman Demirel University, Isparta,Turkey.

b Professor, Department of Prosthodontics, Faculty of Dentistry, University of Hacettepe, Ankara, Turkey. PhD, Research Assistant, Departmant of Prosthodontics, Faculty of Dentistry, University of Erciyes, Kayseri, Turkey.

d Assistant Professor, Department of Chemistry, Faculty of Science, University of Hacettepe, Ankara, Turkey.

- Corresponding author: S. Hakan Tuna Suleyman Demirel Universitesi, Dis Hekimligi Fakultesi, Protetik Dis Ted. AD. Cunur, Isparta,Turkey. Phone: +902462113234 Fax: +902462370607 E-mail: shtunaahotmail.com

\section{INTRODUCTION}

Acrylic resins are widely used in dentistry. Prediction of the service life of acrylic resin material is difficult since many environmental factors affect durability. One of the properties of acrylic resins is water sorption and release, which causes dimensional instability, thereby subjecting the material to internal stresses that may result in crack formation and, eventually, fractures of the denture. ${ }^{1,2}$ Because water interacts with the polymer chains, it may produce some effects such as reversible loosening or effective plasticization of the structure, solvation or reversible rupture 
of weak interchain bonds, and irreversible disruption of the polymer matrix. Therefore, the water sorption and solubility are the critical problems that affects durability. ${ }^{3}$ Takahashi et $\mathrm{al}^{4}$ found that water molecules spread between the macromolecules of the material, forcing them apart. This behavior affects dimensional behavior and denture stability; therefore, water sorption and solubility of these materials should be as low as possible. ${ }^{5}$ Many studies on the water sorption of denture resin have been conducted, and concluded that sorbed water would cause the decrease of mechanical properties. ${ }^{2,6-10}$

Ideally, polymer networks should be insoluble materials with relatively high chemical and thermal stability. However, most of the monomers used in dental resin materials can absorb water and chemicals from the environment, and also release components into the surrounding environment. Both water sorption and solubility would lead to a variety of chemical and physical processes that may result in deleterious effects on the structure and function of dental polymers. ${ }^{11}$ Denture base acrylic resins have low solubility, and the little that occurs is a result of the leaching out of traces of unreacted monomer and water-soluble additives into the oral fluids. However, these monomers sometimes produce a soft tissue reaction. ${ }^{12}$ It is important to determine the residual monomer content and solubility of the tested materials as these properties influence the allergy susceptibility of these materials. ${ }^{13-16}$
The water sorption and water solubility were determined according to the International Standards Organization (ISO) standards 1567:1999. ${ }^{17}$ According to this specification, water sorption should not exceed $32 \mu \mathrm{g} / \mathrm{mm}^{3}$ for heat-cured or self-cured materials. The loss in mass per unit volume (soluble material) should not exceed $1.6 \mu \mathrm{g} / \mathrm{mm}^{3}$ for heat-cured and $8.0 \mu \mathrm{g} /$ $\mathrm{mm}^{3}$ for self-cured materials. ${ }^{17,18}$

Due to the importance of these properties in the clinical and mechanical performance of an acrylic material, this study evaluated water sorption and solubility of different acrylic resins.

\section{MATERIALS AND METHODS}

Ten commercially acrylic materials (two heatcure and eight self-cure acrylic materials) were evaluated in this study. The names of the resins, manufacturers and polymerization conditions recommended by the manufacturers are listed in Table 1.

Three square shaped $1.5 \mathrm{~mm}$ thickness, 2x2 $\mathrm{cm}$ ) specimens of each material were prepared for each polymerization type. All materials were manipulated according to the manufacturer's instructions. One surface of the specimens was polished with using progressively smoother aluminum oxide papers (numbers 280,400 , and 600, Model 189; Atlas, Istanbul, Turkeyl the other surfaces were not. The specimens were set for the recommended set time and technique. Specimens were kept at room temperature for

Table 1. The used materials.

\begin{tabular}{l|cr}
\hline No & Material & Description, Manufacturer \\
\hline 1 & DE Trey QC-20 & Heat-cure acrylic resin Dentsply De trey, Brasil \\
2 & Meliodent Heat Cure & Heat-cure acrylic resin Heraus Kulzer, Wehrheim / TS \\
3 & Meliodent Cold & Self-cure acrylic resin Heraus Kulzer, Ltd, Newbury, UK. \\
4 & Akrileks & Self-cure acrylic repair resin Atlas, England \\
5 & Akribel & Self-cure denture acrylic resin Atlas-Enta AS-İzmir, Turkey \\
6 & Akribel Transparent & Self-cure denture acrylic resin Atlas-Enta AS-Izmir, Turkey \\
7 & Vertex Trayplast & Self-cure custom tray material Vertex-Dental B.V., Netherland \\
8 & Formatray & Self-cure custom tray material Kerr, Italia SPA \\
9 & Dentalon Plus & Self-cure provisional crown material Heraus Kulzer, Hanau, Germany \\
10 & Palavit G & Self-cure pattern resin Heraus Kulzer, Hanau, Germany \\
\hline
\end{tabular}


$30 \mathrm{~min}$. This weight value was considered the initial weight of the specimen (M1) All specimens were weighed daily on an analytical scale (Model JK-180; Chyo, Tokyo, Japan) with an accuracy of $0.0001 \mathrm{~g}$, in a water bath maintained at $37^{\circ} \mathrm{C}$, until a constant weight (M2) was achieved. The specimens were dried in vacuum oven at $37^{\circ} \mathrm{C}$ to constant weight and weighed again (M3).

The values for water sorption (Wsp) and solubility (Wsl), in $\mu \mathrm{g} / \mathrm{mm}^{3}$ for each of the specimens were calculated using the following equations:

Wsp= M2-M3 / V and Wsl=M1-M3 / V

Where $M 1$ is the conditioned mass, in $\mu \mathrm{g}$, prior to immersion in water; $\mathrm{M} 2$ is the mass of the specimen, in $\mu \mathrm{g}$, after immersion in water; M3 is the reconditioned mass of the specimen, in $\mu \mathrm{g}$ after dry and $\mathrm{V}$ is the volume of the specimen $\mathrm{mm}^{3}$.

The mean values of the Wsp and Wsl properties evaluated using One-way ANOVA test. Tukey test used to detect the differences of the mean values of the materials. Pearson correlation coefficient used to view the correlation between Wsp and Wsl properties.

Some specimens were broken for Scanning Electron Microscopy (SEM) analysis. SEM (Jeol JSM 5600LV, Japan) was used at $x 500$ or $\times 1000$ magnification on the surface of the fractured surfaces (Figures 1-10)

\section{RESULTS}

The means and standard error of means of solubility and sorbtion values are shown in Table 2. Water sorption mean values varied from $11.33 \pm 0.33 \mu \mathrm{g} / \mathrm{mm}^{3}$ to $30.46 \pm 0.55 \mu \mathrm{g} / \mathrm{mm}^{3}$. Water solubility mean values varied from $-0.05 \pm 0.23$ to $3.69 \pm 0.12 \mu \mathrm{g} / \mathrm{mm}^{3}$.

One-way analysis of variance for both WSp and Wsl properties suggested that there is significant difference among mean values of materials $(P<.01)$.

Results of Tukey test are shown by bold Roman letters in Table 2. For sorption; material 7 exhibited highest mean value $\left(30.46 \mu \mathrm{g} / \mathrm{mm}^{3}\right.$ ) though material 9 exhibited least mean value $\left(11.33 \mu \mathrm{g} / \mathrm{mm}^{3}\right)$. There was no statistically significant among materials 1, 2, 3 and 10; between materials 3 and 8; among materials 4, 5 and 6 .

For solubility; materials 2 and 10 exhibited negative mean values, respectively $-0.05 \mu \mathrm{g} /$ $\mathrm{mm}^{3}$ and $-0.09 \mu \mathrm{g} / \mathrm{mm}^{3}$. Material 5 exhibited highest mean value $\left(3.69 \mu \mathrm{g} / \mathrm{mm}^{3}\right)$. There was no statistically significant among materials 1, 2, 3, 4, 9 and 10; and among materials 5, 6, 7 and 8.

Pearson correlation coefficient between Wsp and Wsl properties was estimated to 0.285 and no statistically significant. Thus between Wsp and Wsl values, there is no linear correlation.

According to SEM images, materials 1, 3 and 6 had homogeneous structure. However, material 7 and 8 found porous materials than the others.

Table 2. Means of water sorption (Wsp) and water solubility (Wsl) in $\mu \mathrm{g} / \mathrm{mm}^{3}$.

\begin{tabular}{lcccc}
\cline { 2 - 5 } Msp $\left(\mu \mathrm{g} / \mathrm{mm}^{3}\right)$ & \multicolumn{2}{c}{ Wsl $\left(\mu \mathrm{g} / \mathrm{mm}^{3}\right)$} \\
\hline 1 & Mean \pm SD & SE Mean & Mean \pm SD & SE Mean \\
2 & $19.76 \pm 0.45 \mathrm{c}$ & 0.26 & $0.22 \pm 0.52 \mathrm{c}$ & 0.30 \\
3 & $19.60 \pm 0.08 \mathrm{c}$ & 0.05 & $-0.05 \pm 0.23 \mathrm{c}$ & 0.14 \\
4 & $18.54 \pm 0.14 \mathrm{~cd}$ & 0.08 & $0.43 \pm 0.24 \mathrm{c}$ & 0.14 \\
5 & $22.07 \pm 0.72 \mathrm{~b}$ & 0.42 & $1.82 \pm 0.44 \mathrm{bc}$ & 0.26 \\
6 & $21.56 \pm 0.41 \mathrm{~b}$ & 0.24 & $3.69 \pm 0.12 \mathrm{a}$ & 0.07 \\
7 & $21.09 \pm 0.28 \mathrm{~b}$ & 0.16 & $3.55 \pm 0.99 \mathrm{ab}$ & 0.58 \\
8 & $30.46 \pm 0.55 \mathrm{a}$ & 0.32 & $2.34 \pm 0.20 \mathrm{~b}$ & 0.12 \\
9 & $17.70 \pm 0.54 \mathrm{~d}$ & 0.32 & $3.03 \pm 0.48 \mathrm{ab}$ & 0.28 \\
10 & $11.33 \pm 0.33 \mathrm{e}$ & 0.20 & $1.04 \pm 0.23 \mathrm{c}$ & 0.14 \\
\hline
\end{tabular}

Same bold roman letters (a-d) in the columns indicates no statistically significant difference. 


\section{DISCUSSION}

In the present study, the method that recommended by ISO for measuring water sorption and solubility was used. The water sorption was determined according to increase in mass per unit volume. Also water solubility was determined according to loose of mass from polymers. ${ }^{17,18}$

The soluble materials present in acrylic resins are initiators, plasticizers, and free monomer. It has been suggested that there might be a correlation between residual monomer and the weight loss determined by the solubility test. ${ }^{18}$ The largest amount of residual monomer is usually leached from acrylate within the first few days of water storage. Consequently, it might be difficult to estimate the effect of residual monomer release from acrylate with the ISO standardized solubility test. ${ }^{18}$

Acrylic resins absorb water slowly over a period

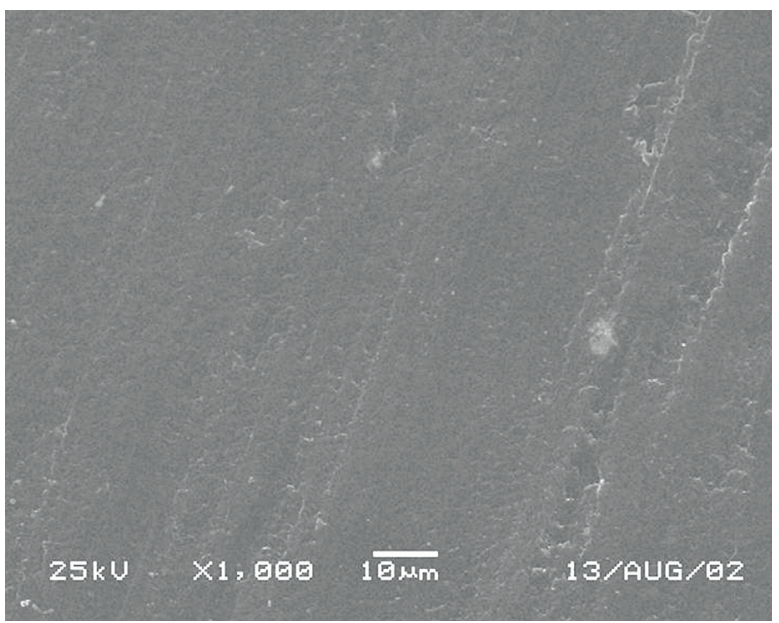

Figure 1. OSEM photographs illustrating fractured surface of DE Trey QC-20 specimen.

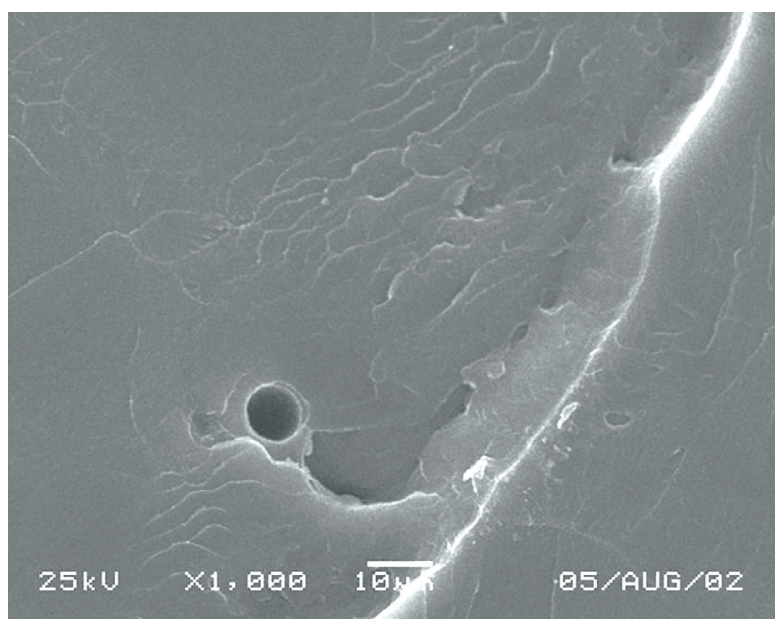

Figure 3. SEM photographs illustrating fractured surface of Meliodent Cold specimen. of time, primarily because of the polar properties of the resin molecules. High equilibrium uptake of water can soften an acrylic resin because the absorbed water can act as a plasticizer of acrylate and reduce the strength of the material. ${ }^{10}$ The extent and rate of water uptake into polymer networks are predominantly controlled by resin polarity, dictated by the concentration of polar sites available to form hydrogen bonds with water; and network topology. ${ }^{11,19}$ Arima et al ${ }^{20}$ suggested that the chemical nature of the polymer versus that of the water molecule directly affected the water sorption of resin. Water is absorbed into polymer by the polarity of the molecules in the polymers by unsaturated bonds of the molecules or unbalanced intermolecular forces in the polymers. According to Dixon et al, ${ }^{21}$ the residual monomer could affect water sorption and expansion.

In the present study a provisional crown

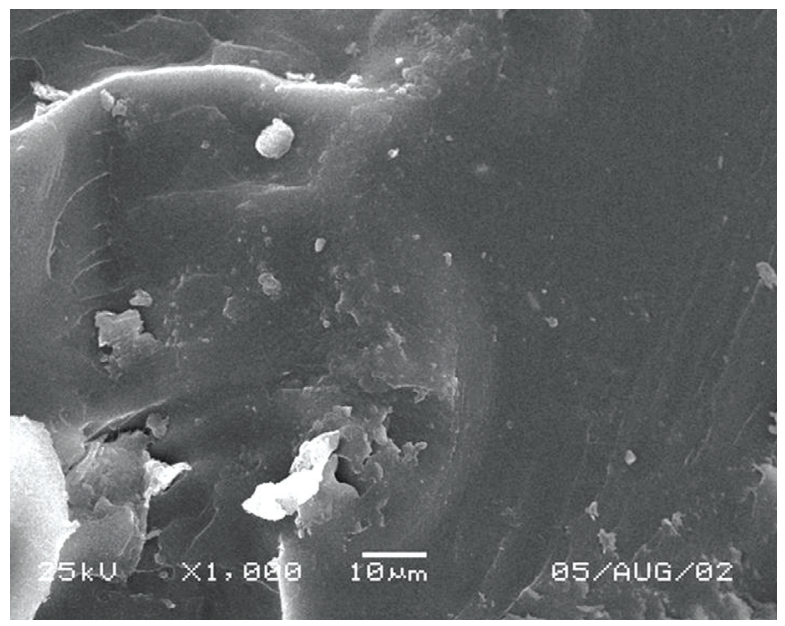

Figure 2. SEM photographs illustrating fractured surface of Meliodent Heat Cure specimen.

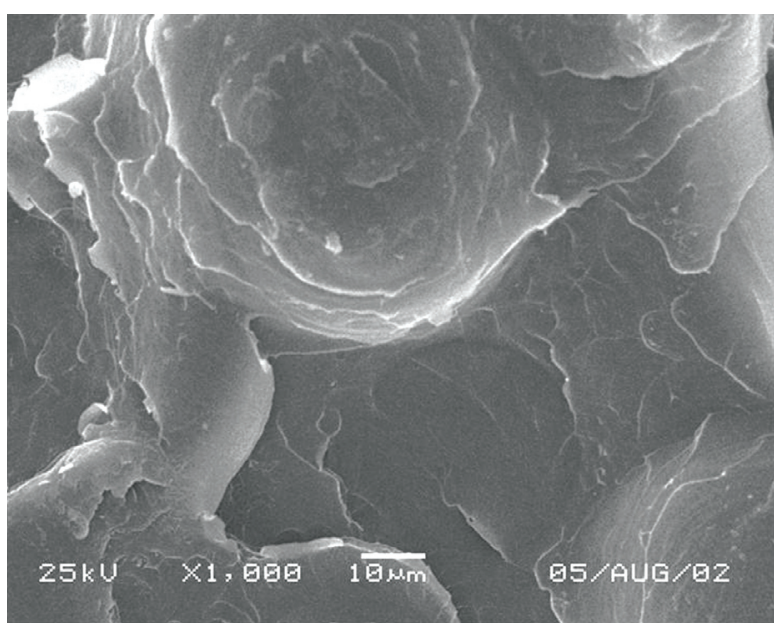

Figure 4. SEM photographs illustrating fractured surface of Akrileks specimen. 
material, material 9 had the least water sorption value $\left(11.33 \mu \mathrm{g} / \mathrm{mm}^{3}\right)$. Materials 2 and 10 had negative solubility values. The water that was absorbed by these materials could not be released. It can be concluded that these materials or their contents bond water molecules chemically.

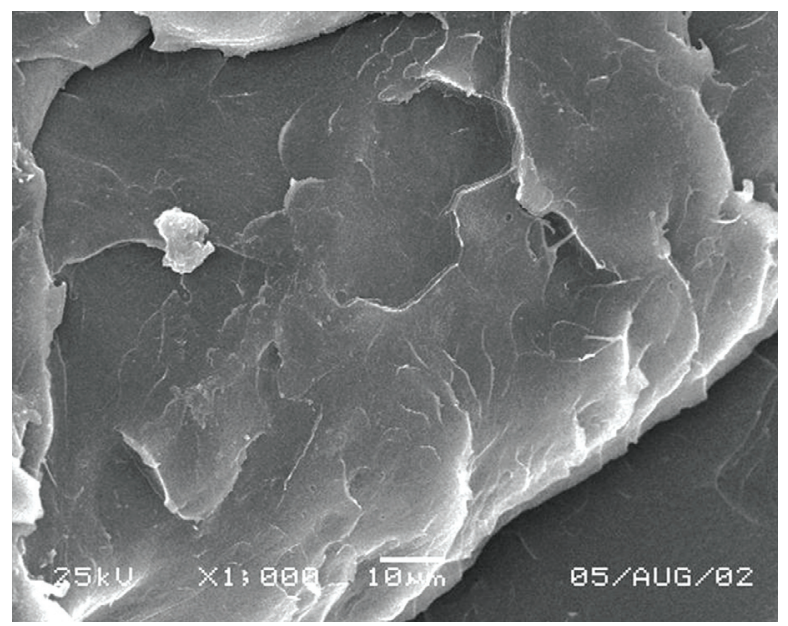

Figure 5. SEM photographs illustrating fractured surface of Akribel specimen.

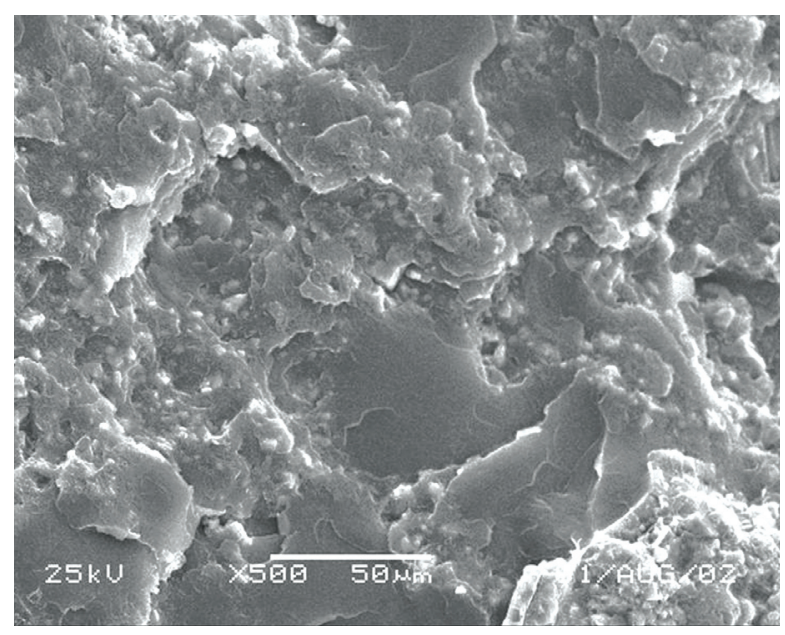

Figure 7. SEM photographs illustrating fractured surface of Vertex Trayplast specimen.

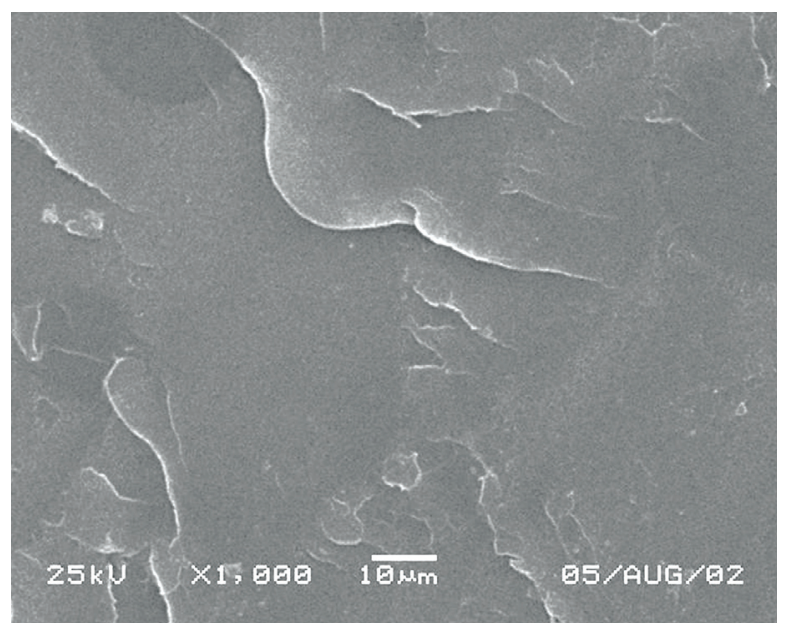

Figure 9. SEM photographs illustrating fractured surface of Dentalon Plus specimen.
Also the dimensional stability of the tray material is an important fact. As mentioned before the water sorbtion influences the dimensional stability. In the present study, material 7 is a custom tray material. Its sorption and also solubility values $\left(30.46 \mu \mathrm{g} / \mathrm{mm}^{3}\right.$ and $\left.2.34 \mu \mathrm{g} / \mathrm{mm}^{3}\right)$

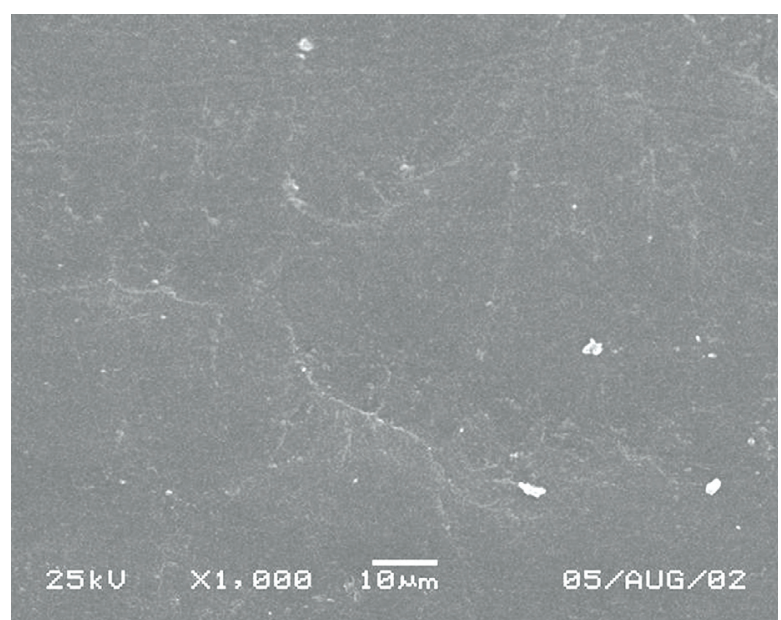

Figure 6. SEM photographs illustrating fractured surface of Akribel Transparent specimen.

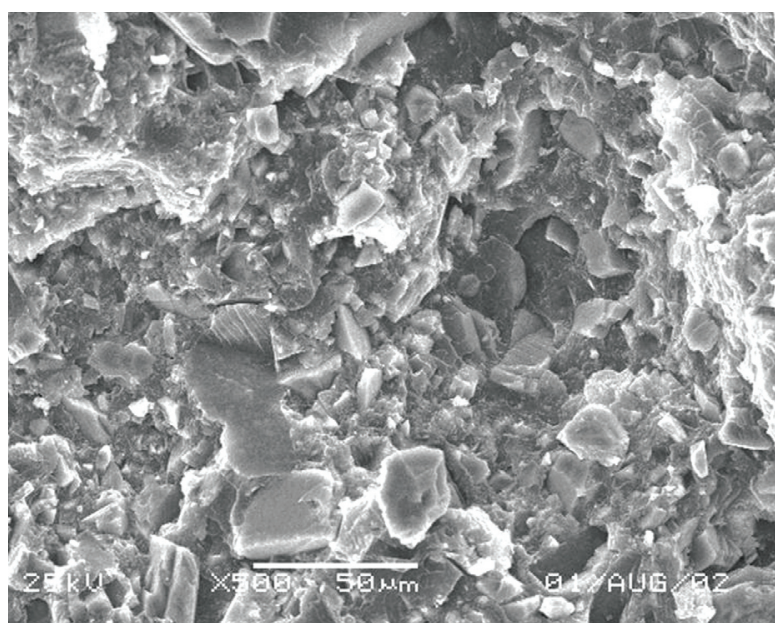

Figure 8. SEM photographs illustrating fractured surface of Formatray specimen.

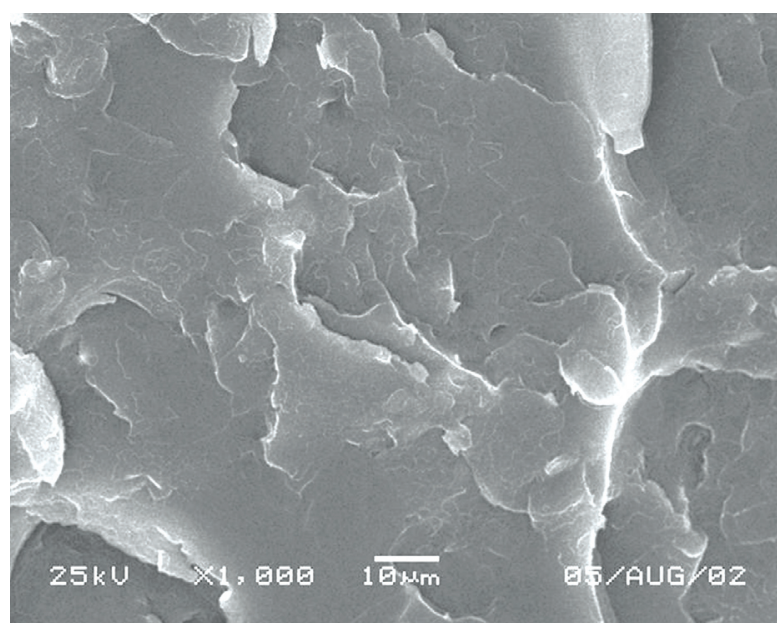

Figure 10. SEM photographs illustrating fractured surface of Palavit $\mathrm{G}$ specimen. 
was high. Material 8 (tray material) had the lower water sorption value $\left(17.70 \mu \mathrm{g} / \mathrm{mm}^{3}\right)$ than most of the tested resins. But its solubility value $(3.03 \mu \mathrm{g} /$ $\mathrm{mm}^{3}$ ) was high (Table 2).

The principal difference between self-cure resins and heat-cure resins is that more residual monomer is present in the self-cure resins. Also, with a high monomer to polymer ratio, residual monomer content in the polymerized acrylic resin would be large. ${ }^{12}$ Fletcher et al $^{22}$ found that selfcure resins exhibited higher residual monomer levels than did heat-cure resins. These higher residual monomer contents could be related to the higher solubility levels of self-cure resins reported. It is obvious that the greater amount of residual monomer in self-cure PMMA also affects the solubility values more than heat-cure PMMA does, of which the residual monomer content is considerably lower. ${ }^{18}$ In the present study, heat cure acrylic resins had lower solubility values than mosf of the self-cure acrylic resins.

The results of the water sorption and solubility either self-cure or cold-cure acrylic resins were in accordance with the ISO specification. ${ }^{17}$ According to earlier studies the water sorption of different types of acrylates is 10 to $25 \mu \mathrm{g} / \mathrm{mm}^{3}{ }^{3}{ }^{7,10,18,20} \mathrm{In}$ the present study the water sorption values were in accordance with mentioned studies except material 7 (tray material).

According to SEM images, materials 7 and 8 (Figures 7 and 8) were found non-homogeneous materials. They had a decreased porosity compared to others. Miettinen and Vallittu ${ }^{18}$ stated that water sorption and solubility of polymers depended on the homogenity of the material. The more homogeneous a material, the less water it absorbs and the less soluble it is. ${ }^{23} \mathrm{~A}$ high amount of porosity will facilitate fluid transport in and out of the network, leading to enhanced water uptake and elution. ${ }^{11}$

\section{CONCLUSIONS}

According to tests performed in this research, each acrylic resin displayed various water sorption and water solubility values. The results of the water sorption and solubility of both self-cured and heat-cured acrylic resins were in accordance with the ISO specification. No correlation found between water sorption and water solubility values.

\section{REFERENCES}

1. Hiromori K, Fujii K, Inoue K. Viscoelastic properties of denture base resins obtained by underwater test. $J$ Oral Rehabil 2000;27:522-531.

2. Wong DM, Cheng LY, Chow TW, Clark RK. Effect of processing method on the dimensional accuracy and water sorption of acrylic resin dentures. J Prosthet Dent 1999;81:300-304

3. Garcia-Fierro JL AJ. Sorption of water by epoxide prepolymers. Macromolecules 1982;15:1145.

4. Takahashi Y, Chai J, Kawaguchi M. Effect of water sorption on the resistance to plastic deformation of a denture base material relined with four different denture reline materials. Int J Prosthodont 1998;11:49-54.

5. Cucci AL, Vergani CE, Giampaolo ET, Afonso MC. Water sorption, solubility, and bond strength of two autopolymerizing acrylic resins and one heat-polymerizing acrylic resin. J Prosthet Dent 1998;80:434-438.

6. Hargreaves AS. Equilibrium water uptake and denture base resin behaviour. J Dent 1978;6:342-352.

7. Ristic B, Carr L. Water sorption by denture acrylic resin and consequent changes in vertical dimension. $J$ Prosthet Dent 1987;58:689-693.

8. Kalachandra S, Turner DT. Water sorption of plasticized denture acrylic lining materials. Dent Mater 1989;5:161164.

9. Patel MP, Braden M. Heterocyclic methacrylates for clinical applications. III. Water absorption characteristics. Biomaterials 1991;12:653-657.

10. Barsby MJ. A denture base resin with low water absorption. J Dent 1992;20:240-244.

11. Malacarne J, Carvalho RM, de Goes MF, Svizero N, Pashley DH, Tay FR, Yiu CK, Carrilho MR. Water sorption/solubility of dental adhesive resins. Dent Mater 2006;22:973-980.

12. Craig RG OBW, Powers JM. . Dental materials. Properties and manipulation. Plastics in prosthetics. 5 ed. St Louis: CV Mosby; 1992.

13. Vilaplana J, Romaguera C, Cornellana F. Contact dermatitis and adverse oral mucous membrane reactions related to the use of dental prostheses. Contact Dermatitis 1994;30:8084.

14. Alanko K, Kanerva L, Jolanki R, Kannas L, Estlander T. Oral mucosal diseases investigated by patch testing with a dental screening series. Contact Dermatitis 1996;34:263267

15. Kanerva L, Jolanki R, Estlander T. 10 years of patch testing with the (meth)acrylate series. Contact Dermatitis 1997;37:255-258.

16. Geukens S, Goossens A. Occupational contact allergy to (meth)acrylates. Contact Dermatitis 2001;44:153-159. 
17. ISO 1567:1999 Denture Base Polymers.

18. Miettinen VM, Vallittu PK, Docent DT. Water sorption and solubility of glass fiber-reinforced denture polymethyl methacrylate resin. J Prosthet Dent 1997;77:531-534.

19. Unemori M, Matsuya Y, Matsuya S, Akashi A, Akamine A. Water absorption of poly(methyl methacrylate) containing 4-methacryloxyethyl trimellitic anhydride. Biomaterials 2003;24:1381-1387.

20. Arima T, Murata H, Hamada T. The effects of cross-linking agents on the water sorption and solubility characteristics of denture base resin. J Oral Rehabil 1996;23:476-480.

21. Dixon DL, Breeding LC, Ekstrand KG. Linear dimensional variability of three denture base resins after processing and in water storage. J Prosthet Dent 1992;68:196-200.

22. Fletcher AM, Purnaveja S, Amin WM, Ritchie GM, Moradians $\mathrm{S}$, Dodd AW. The level of residual monomer in self-curing denture-base materials. J Dent Res 1983;62:118-120.

23. Lassila LV, Vallittu PK. Denture base polymer Alldent Sinomer: mechanical properties, water sorption and release of residual compounds. J Oral Rehabil 2001;28:607613. 